\title{
ÁRVORE E IMAGINÁRIO SIMBÓLICO COMO LUGAR POÉTICO DE MEMÓRIA NA PAISAGEM
}

\author{
Tree and symbolic imaginary as poetic place of memory in the landscape \\ Árbol e imaginario simbólico como lugar poético de memoria en el paisaje
}

Jorge Crichyno

Universidade Federal Fluminense (UFF)

\begin{abstract}
Resumo
O tema tratado neste estudo refere-se ao lugar poético da árvore no imaginário arquetípico e suas ressonâncias na memória da paisagem, buscando elucidar os valores e os significados simbólicos capazes de evocar referências nos sujeitos imaginantes. A árvore é um elemento extremamente enriquecedor da paisagem e sua presença é uma forma de reaproximar os sujeitos da natureza aliando o prosaico ao poético, retomando a ligação existente desde tempos ancestrais. $\mathrm{Na}$ compreensão desses valores simbólicos e arquetípicos, buscamos a imersão da dimensão fenomenológica da árvore na memória paisagem. Pelos caminhos do imaginário, as forças oníricas e as pulsões inconscientes nos conduzem para uma fusão dos sujeitos com a memória da paisagem, possibilitando a aventura da percepção e o devaneio do imaginário arbóreo.
\end{abstract}

Palavras-chaves: Árvore; Imaginário; Lugar Poético; Memória; Paisagem.

\begin{abstract}
The theme dealt with in this study refers to the poetic place of the tree in the archetypal imaginary and its resonances in the memory of the landscape, seeking to elucidate the values and the symbolic meanings capable of evoking references in the imaginary subjects. The tree is an extremely enriching element of the landscape and its presence is a way to re-approximate the subjects of nature by linking the prosaic to the poetic, retaking the connection existing from ancestral times. In understanding these symbolic and archetypal values, we seek to immerse the phenomenological dimension of the tree in the landscape memory. Through the paths of the imaginary, the dream forces and unconscious impulses lead us to a fusion of the subjects with the memory of the landscape, making possible the adventure of perception and the reverie of the arboreal imaginary.
\end{abstract}

Keywords: Tree; Imaginary; Poetic Place; Memory; Landscape.

\section{Resumen}

El tema tratado en este estudio se refiere al lugar poético del árbol en el imaginario arquetípico y sus resonancias en la memoria del paisaje, buscando 
elucidar los valores y los significados simbólicos capaces de evocar referencias en los sujetos imaginantes. El árbol es un elemento extremadamente enriquecedor del paisaje y su presencia es una forma de reaproximar a los sujetos de la naturaleza aliando lo prosaico al poético, retomando la conexión existente desde tiempos ancestrales. En la comprensión de esos valores simbólicos y arquetípicos, buscamos la inmersión de la dimensión fenomenológica del árbol en la memoria del paisaje. Por los caminos del imaginario, las fuerzas oníricas y las pulsiones inconscientes nos conducen hacia una fusión de los sujetos con la memoria del paisaje, posibilitando la aventura de la percepción y el devaneo del imaginario arbóreo.

Palabras claves: Árbol; Imaginario; Lugar Poético; Memoria; Paisaje.

\section{INTRODUÇÃO}

As árvores evocam significados relacionados aos aspectos simbólicos do lugar e aos aspectos emocionais dos sujeitos, a partir de sua capacidade de marcar e lembrar momentos das vidas humanas ou representar simbolicamente o lugar poético na paisagem.

As árvores influem no imaginário dos sujeitos e no coletivo social, gerando poesia, mistério, memória e espiritualidade, significando a essência da vida. Cada sujeito observa uma árvore de forma diferente, numa interpretação pessoal, estabelecendo uma interdependência, e a cultura tem um papel influenciador nesta forma de olhar (Lewis, 1990).

Aliadas a isso, entretanto, estão questões referentes à essência da árvore, que também atuam sobre esse olhar e são as responsáveis pelo caráter universal de diversos significados da imagem-árvore. Assim, as árvores desempenham um papel de destaque na paisagem pelo fato de serem capazes de estabelecerem uma referência direta aos valores de identidade, indispensável para que os sujeitos associem significados simbólicos ao conceito de lugar poético. A paisagem é um instante na luz do olhar que sonha.

Compreendemos que as árvores, atuam também como marcos históricos e simbólicos que se reportam à memórias passadas (Spirn, 1984), e acumulam significados por serem entidades que passam por várias gerações (Davies, 2002). Pela longevidade, as árvores simbolizam os ciclos de vida e a continuidade da historicidade e da geograficidade (Dardel, 1952), e são memórias vivas, como é o exemplo relacionado à Árvore da Páscoa.

Portanto, este artigo procura compreender a importância da árvore, única, monumental, no que se refere a um culto ou comemoração, por exemplo, concernente ao período da Páscoa na tradição judaico-cristã, de conexão ao sentido de morte/ressureição e de espiritualidade, presentes na memória cultural dos sujeitos.

Ao incursarmo-nos pelos meandros do imaginário arbóreo é fundamental a visualização dos diferentes planos imagéticos que o permeiam. Este procedimento significa 
abranger desde a imagem pura da árvore às suas ressignificações no contexto cultural e urbano, o que implica que este estudo transite por searas de caráter diferenciado.

Compreendemos esse nível como fundamental pelo fato de o tema aqui discutido tratar da árvore no ambiente urbano, mas que, não podemos deixar de considerar o aporte da abordagem poética e simbólica arquetípica, extremamente importante no caso do imaginário arbóreo.

Esta proposta de abordagem surge, portanto, como uma tentativa de abarcar a complexidade imanente da potência imagética da árvore na paisagem. Ressaltamos que essa abordagem espelha os valores epistemológicos referentes ao imaginário.

\section{IMAGEM-ÁRVORE E O CORAÇÃO DA ÁRVORE}

Ao buscarmos um percurso de apreensão do imaginário arbóreo, vemos, a partir do caminho indicado por Bachelard (2004) a importância de entrarmos em contato com a imagem pura, que no contexto do imaginário arbóreo, chamamos de imagem-árvore.

A árvore que se apresenta à nossa percepção não é a forma em nosso interior, imagem esta que será diferente para cada sujeito que observa, pois passa a incluir a afecção (Bergson, 1953), ou seja, aquilo que misturamos do nosso corpo à imagem dos corpos exteriores. Na árvore percepcionada, está incluído no olhar particular, realçando o que nela mais nos atrai, o que mais nos sensibiliza e com o que mais nos identificamos, por exemplo, em relação ao seu lugar poético na paisagem.

A árvore percepcionada provém da presentação do objeto árvore, a partir da qual são geradas diversas sensações no sujeito imaginante. Essas sensações são pontuadas por nossa subjetividade, a árvore vivida, de nossas lembranças, que são (re)presentação da memória. A subjetividade das qualidades sensíveis da árvore consiste, sobretudo, numa espécie de contração do real, operada por nossa memória (Bergson, 1953).

Segundo Wunenburger (1997), a percepção visual como é compreendida por Bergson, ou como é vista por outros autores - uma retirada de informações de uma parte da exterioridade - parece ressaltar um recorte parcial, uma limitação tanto de informações próprias do mundo como das imagens constitutivas do sujeito (Wunenburger, 1997).

O potencial intrínseco da árvore, sua essência, entretanto, é o responsável pela repetição, nas mais diferentes culturas, de certos significados de sua imagem. Pois, por mais que estejamos afastados de seu valor imanente e a ele acrescentarmos nossas vivências subjetivas e culturais do lugar poético na paisagem, ele estará sempre presente, agindo sobre todas as camadas simbólicas que a ele se sobreponham (Crichyno, 2016). 
Nesse contexto, podemos exemplificar a Árvore da Páscoa, que constitui uma tradição de origem alemã, e vem sendo cultivada na memória cultural da região sul do Brasil. Descendentes alemães de Santa Catarina preparam Árvores da Páscoa feitas com casca de ovos vazias e decoradas lindamente, que ornamentam também o interior das casas. A maior Árvore da Páscoa do mundo está em Pomerode, no Vale do Itajaí.

No Brasil a tradição da Osterbaum chegou com os imigrantes e até hoje é cultivada em algumas cidades principalmente em Pomerode, em Santa Catarina. A Árvore da Páscoa é montada com um galho seco, que simboliza a frieza e morte do sepulcro de Jesus Cristo. No galho são colocadas cascas de ovos coloridas, que simbolizam a alegria da vida que significa a Ressurreição de Jesus. Os ovos são colocados na Árvore da Páscoa porque o ovo significa ou simboliza que há vida dentro dele e dali ela brota, apesar de estar escondida até o momento em que a ruptura acontece. Dentro do ovo está a vida nova que surge para a luz do sol.

A Páscoa é uma das mais antigas celebrações cristãs, mas tem sua origem em antigos ritos pagãos. Muito comuns especialmente na Baviera, Baden-Wütenberg e Rheinland, após a unificação das Alemanhas muitos costumes voltaram a ser praticados em todo país. O símbolo do ovo de Páscoa tem sua origem no significado do renascimento, pois representa a fertilidade. Desde o século XII ele tem o costume de ser cozido e pintado para ser usado na decoração. Esses ovos coloridos podiam também ser pendurados em árvores, muitas vezes ainda secas do inverno, "dando vida" novamente a elas - Osterbaum.

Nos galhos da árvore são colocadas cascas de ovos coloridas, que simbolizam a alegria da vida que significa a Ressurreição de Jesus Cristo. O ovo significa ou simboliza que há vida dentro dele e dali ela brota, apesar de estar escondida até o momento em que a ruptura acontece. Dentro do ovo está a vida. A Páscoa é Vida, Ressurreição, Esperança e Alegria, apesar da Sexta-feira Santa com a crucificação de Jesus. "Eu vivo, vós também vivereis", é a sua mensagem gloriosa. O Osterbaum é assim apenas um símbolo, pois os cristãos celebram e adoram o Salvador Jesus Cristo.

As famílias adotam este costume em seus lares, assim como já fazem com a árvore de Natal. O processo é simples: Semanas antes da Páscoa são reservadas cascas de ovos com apenas um furo pequeno, pelos quais são retirados os conteúdos dos ovos e, posteriormente, são lavados e deixados para secar de cabeça para baixo. Os desenhos e pinturas representam símbolos religiosos ou motivos para as crianças. As cascas dos ovos são pintadas com tinta plástica.

Na Sexta-feira Santa, são colocados em um vaso um galho totalmente seco, sem nenhuma folha, deixando-o exposto em local visível na casa para finalmente, no Domingo de Páscoa, é ornamentado e pendurado os ovos. A árvore da Páscoa (Osterbaum) pode ser retirada a partir do segundo Domingo após a Páscoa (Figura 1, 2 e 3). 


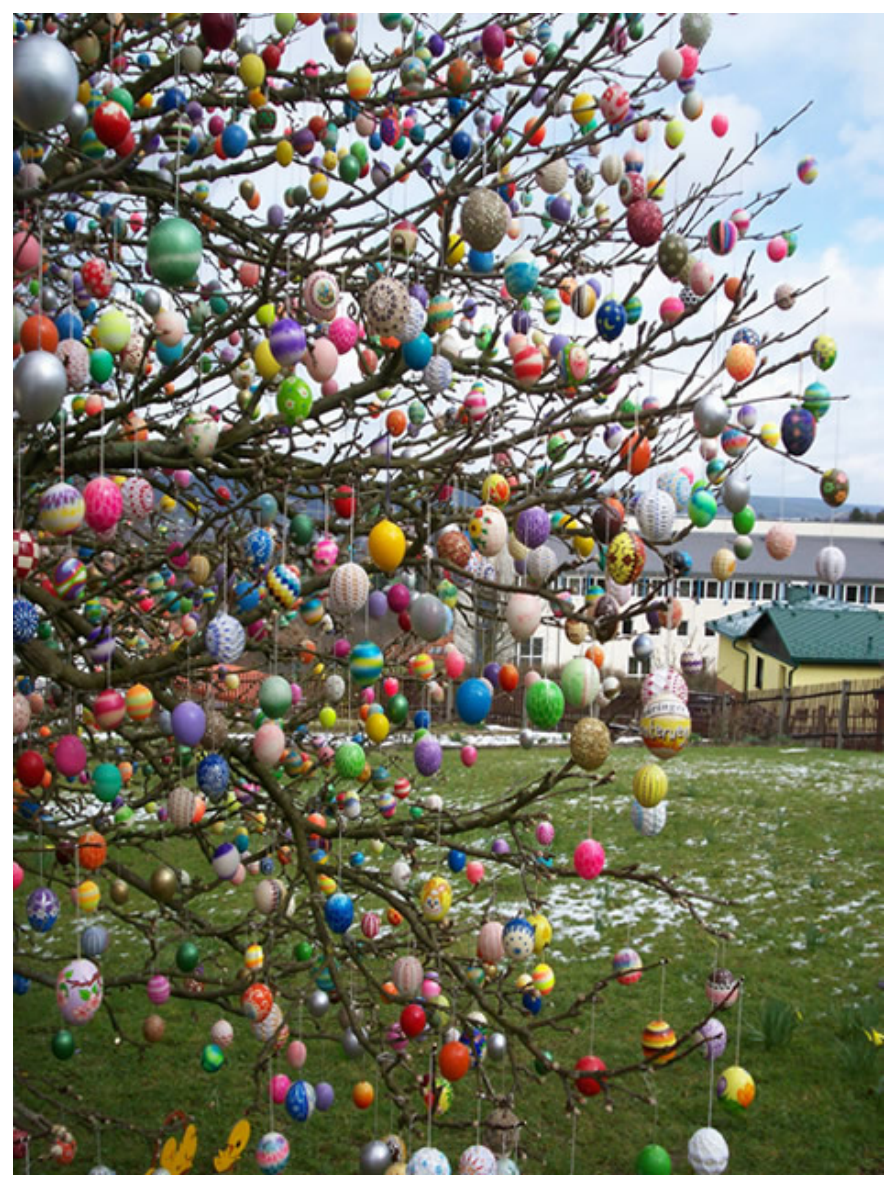

Figura 1: Osterbaum - Árvore da Páscoa.

Fonte: https://www.flickr.com/photos/stmarien/2387891112/sizes///in/photostream

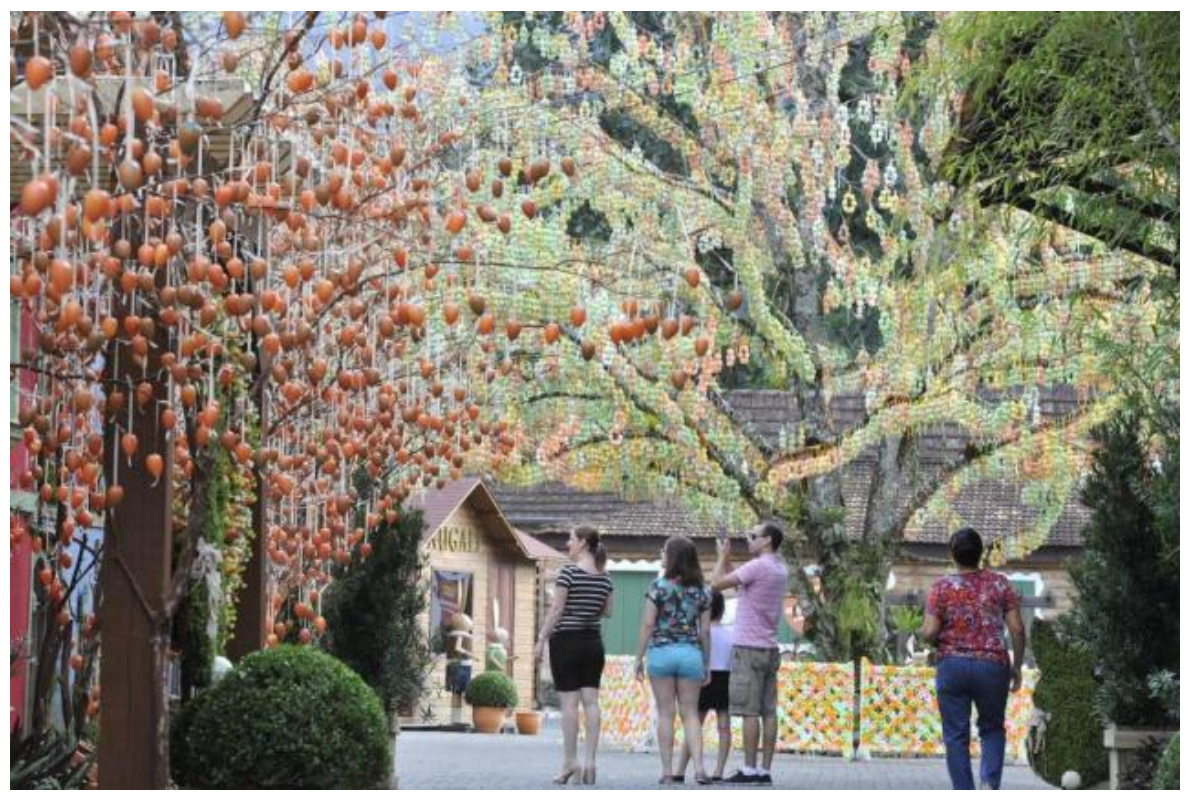

Figura 2: Árvore da Páscoa de Pomerode. Orterfest 2017.

Fonte: http://zh.clicrbs.com.br/rs/vida-e-estilo/noticia/2017/03/osterfest-esperareceber-140-mil-visitantes-em-pomerode-em-santa-catarina-9751539.html 


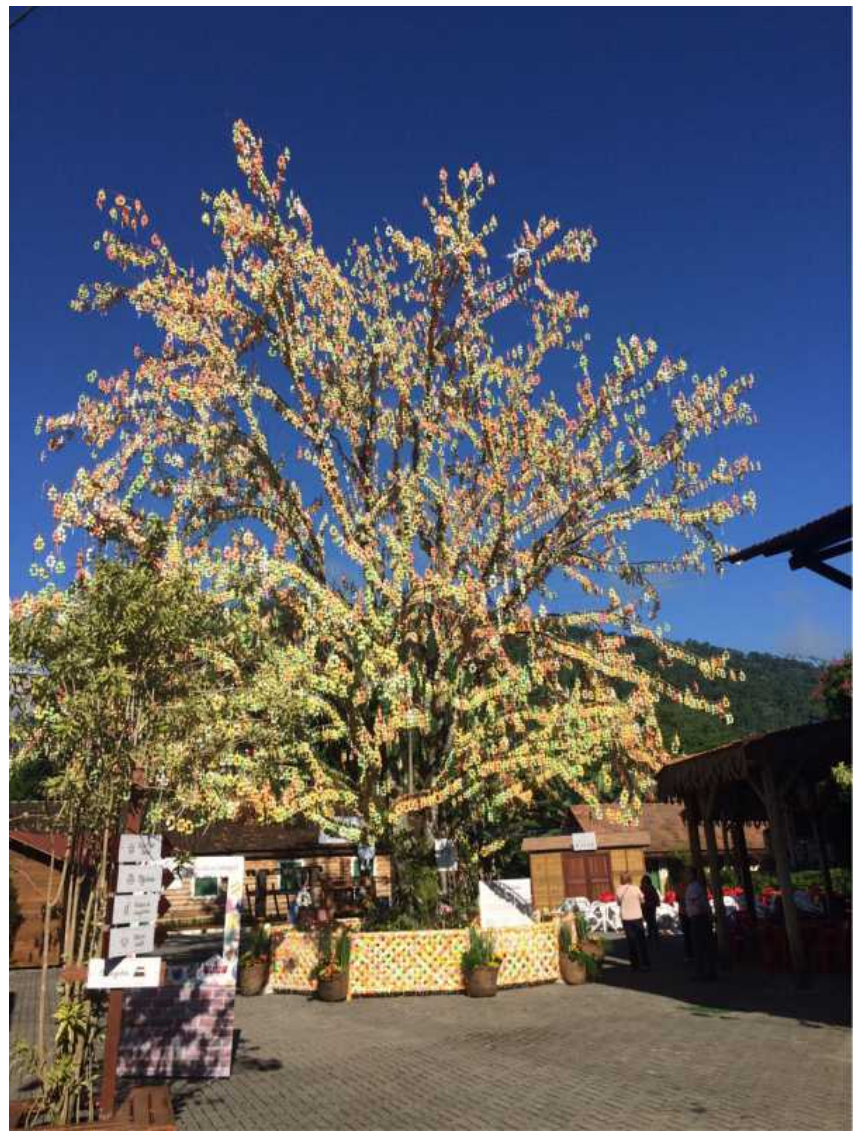

Figura 3: Árvore da Páscoa de Pomerode. Orterfest 2017.

Fonte: https://www.skytourviagens.com.br/blog/novidades/osterdorf-e-osterfest2017. 
Os ovos coloridos representam a alegria da vida nova, a ressurreição de Cristo. De uma beleza delicada e até ingênua, a Árvore da Páscoa vem conquistando admiradores e fãs e a tradição alemã vem ganhando espaço no sul do Brasil, prometendo chegar a novas regiões com muita força e beleza.

Como afirma Bachelard, antes de pensarmos, imaginamos (Bachelard, 2004) e esta imaginação nos permite alcançar tanto a essência, a imagem-árvore, como incorpora, a partir daí, nossa phantasia à sua imagem, criando a Árvore da Páscoa que cresce e chega à morada gigante do céu como lugar poético da existência do ser (Figura 4).

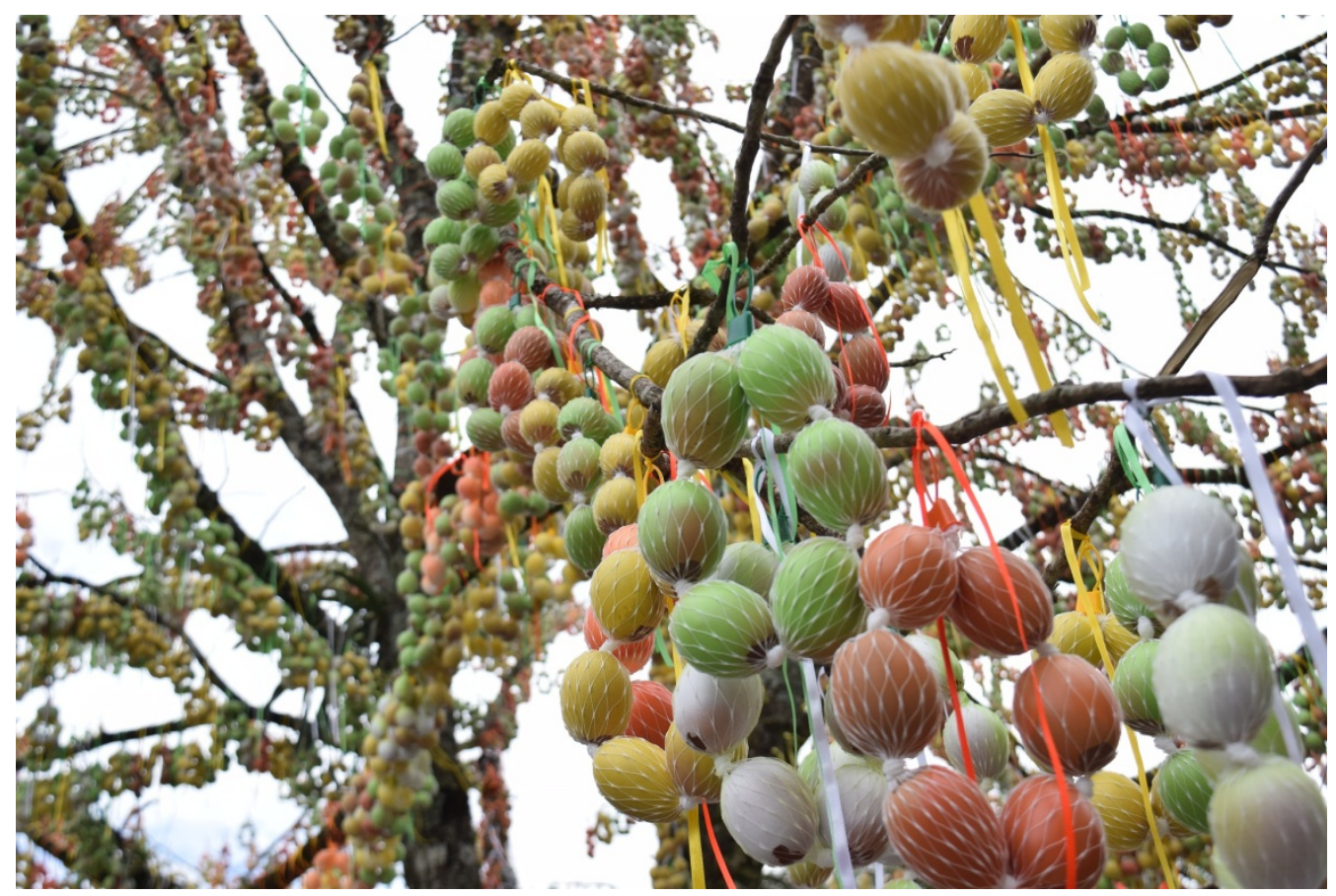

Figura 4: Detalhe da Árvore da Páscoa de Pomerode. Orterfest 2017.

Fonte: https://www.skytourviagens.com.br/blog/novidades/osterdorf-e-osterfest2017

\section{ÁRVORE MEMÓRIA}

A memória é a capacidade de conservar e relembrar, reconhecendo os estados da consciência já vividos (Bergson, 1992), sem, no entanto, desprezar o estado de consciência atual, no qual, segundo Wunenburger, as lembranças, por serem imagens atuais são tão presentes quanto uma imagem perceptiva (Wunenburger, 1997). Nelas é buscado um referencial pertencente a um tempo acabado.

Bergson (1953) considera a percepção como um conjunto de imagens que se relacionam a uma única imagem, à do corpo daquele que realiza a ação de perceber, e que elas são como um meio caminho entre a própria coisa e a presentificação. A percepção é o 
que nos permite através da presença dos sujeitos no lugar e apreender mentalmente um dado exterior à consciência, constituindo assim um ajuste de dois sistemas de imaginário, o do Eu e do Mundo (lugar). De outro modo, a presentificação se dá através da ausência dos sujeitos no lugar.

Segundo Durand (1997), é o processo imaginativo que atua antes da percepção, com sua carga de imediatismo, numa outra dimensão do tempo e que produz conhecimento. Bachelard (2004), também acredita que imaginamos antes de pensar, compreendendo a reverberação da imagem poética, mas sua teoria encontra aí um ponto divergente de Durand, pois, para ele, a imaginação não pressupõe a utilização de conhecimentos anteriores.

O imaginário deve ser compreendido também em relação à memória, pois segundo Bergson (1975), a memória constitui principal aporte da consciência individual na percepção, o lado subjetivo de nosso conhecimento das coisas. Eliminando-se a memória de todas as formas de percepção, tem-se a percepção pura. O autor afirma que "imaginar não é se lembrar, pois uma lembrança que se atualiza se transforma em imagem". Considera, então, que o inverso não é verdadeiro.

O que ocorre é que a memória colore a imaginação com resíduos a posteriori. Bachelard aparta os sentidos da imagem e da lembrança, ressaltando que a imagem é desprendida do passado real, embora gere "realidade". A fenomenologia da imaginação que Bachelard desenvolve, buscando o momento da emersão da imagem poética, considera que as questões implicadas no imaginário, como as experiências vivenciadas no passado e a visão da imagem a partir de um ponto de vista simbólico, são posteriores ao momento da eclosão da imagem poética e não fazem parte dos estudos fenomenológicos da imaginação criadora.

No que concerne à questão arbórea, podemos pensar em dois sentidos opostos. No primeiro, a imagem da árvore é recuperada a partir de processos indutores que a trazem ao estado de consciência, e, no segundo, inversamente, é a presentação arbórea, que faz vir à tona situações, sentimentos, emoções, imagens caras à afetividade. As lembranças, memória transformada em imagens, reforçam o aspecto subjetivo de apreensão do lugar poético na paisagem.

A experiência de lembranças traz "uma nova densidade", uma profundidade suplementar à imagem mental do sujeito imaginante, pois o seu estado afetivo e intelectual é dilatado, carregado de sentido a existência do sujeito, o que nos faz pensar sobre a veemência e importância das emoções que podem aflorar relacionadas a lembranças trazidas pela presença das árvores na paisagem.

Por essa capacidade nata, de rememoração, é muito natural o ser humano esperar do ambiente em que vive as condições que melhor acolham essa capacidade. 
Nesse ponto, é importante a atuação da memória como aspecto coletivo da paisagem. Como bem aponta Sansot $(1989,1983)$, apesar de depender da produtividade de transmissão de uma geração à outra, de um grupo de sujeitos que tenha partilhado determinados eventos e de lugares que não se modifiquem, a memória coletiva pode ressurgir mesmo com as dificuldades que se impõem nos tempos atuais, e com o esquecimento da história.

Sansot acredita que, para alcançar um algo mais da memória, é necessário que a consciência coletiva não se reduza à soma das (re)presentações individuais ou à sua interação, e sim que elas tenham um independência. Segundo Sansot, esses objetos coletivos são elementos que existem na paisagem de forma que cada um de nós pode se apropriar deles, partilhando uma adequação, fazendo coincidir o caminho de cada um com o de outros na paisagem (Sansot, 1989).

No que tange à construção da memória coletiva e simbólica do espaço urbano, Sansot (1989) assinala a participação do inconsciente coletivo, pleno do que não conhecemos. A persistência de certos ritos culturais indica a manifestação de uma constância da natureza - "os arquétipos primordiais que incitam a comportamentos quase idênticos" (Sansot, 1989). Dentre esses arquétipos encontra-se a árvore, capaz de induzir a uma similaridade no comportamento humano e nas relações de coletividade, colocando-se como uma base estrutural à formação das identidades.

As árvores funcionam como esses objetos coletivos, contribuindo, portanto, na constituição dessa memória, pois podem mais facilmente possibilitar uma autonomia da consciência coletiva. Uma árvore de importância histórica e cultural para uma coletividade, como por exemplo, a Árvore da Páscoa, pode pertencer a uma espécie que possua significados pessoais e sociais para um determinado sujeito.

O inconsciente coletivo, também participante dessa memória, pode fazer emergir imagens que o compõem, provocando determinadas lembranças compartilhadas por um grupo de sujeitos, o que Jung atribui à existência de uma universalidade mental dos cérebros humanos, ou seja, a psique coletiva (Jung, 1964).

As árvores que se perpetuam no ambiente urbano, criando relações com o lugar e com os sujeitos, podem constituir imagens que possuam significados poéticos numa determinada paisagem, sendo compartilhados pelos sujeitos de um lugar.

\section{ÁRVORE SIMBÓLICA E IMPLICAÇÕES ARQUETÍPICAS}

A imagem-árvore simbólica vem a ser uma atividade criativa do sujeito imaginante, que não se contenta mais em reproduzir em uma ordem subjetiva, as percepções possíveis, mas que desvela um sentido figurado (Wunenburger, 1997). A 
pluralidade de significados e a independência a um contexto que the dê sentido confere a árvore o estatuto arquetípico. A partir da potência imagética, ela é capaz de remeter a outros objetos e ideias, como um símbolo de acentuada elasticidade.

A imaginação simbólica, segundo Davies (2002) compreende que os símbolos não são arbitrários, tendo uma propriedade nascida de sua significância histórica e de suas características físicas. Isso faz com que, como afirma Wunenburguer (1997), a imagem não esteja somente ligada a conteúdos perceptivos, e sim, possa conferir a um conteúdo ideal uma forma sensível (re)presentada mentalmente.

A árvore está entre os símbolos que, ao nível cultural, fornecem uma linguagem simbólica universável, com padrões facilmente decifráveis. Como um arquétipo "natural", a árvore não depende de estruturas socioculturais para o seu sentido.

Por isso seus significados se mantém acima destes, e não podemos deixar de considerá-los. Por outro lado, as complexas derivações de sentido que surgem a partir da árvore urbana e apropriações culturais são de extrema importância.

$\mathrm{O}$ arquétipo é o modelo primitivo (forma primordial), original, que permite ao pensamento humano fazer emergir ao nível do consciente os símbolos, que se concretizam da forma mais complexa e mesmo distanciada da imagem original (Verjat, 1993). A imagem arquetípica da árvore é, portanto, simples, mas pode se multiplicar infinitamente em símbolo que venham a adquirir os mais diversos significados e valores.

Os símbolos substituem e, assim, representam alguma coisa que, pela sua imaterialidade, necessite ser representada, fazendo estar presente, algo que não está lá (Gadamer, 1976). Eles são fatores geradores de grandes imagens (Bachelard, 2001).

Essa linha de pensamento teórico-conceitual e a metodologia utilizada por Bachelard constituem um dos eixos de base para o estudo em questão, sendo a referência para a análise das criações poéticas e sua vinculação temática da árvore como lugar urbano. Um ponto fundamental na análise do imaginário arbóreo é a compreensão de sua perspectiva simbólica.

A árvore, como símbolo desvela um mundo invisível. Um mundo abstrato, acessível apenas pela imaginação. A árvore na paisagem é uma centelha imaginante, um caminho para penetrar nesse mundo, a partir da materialidade.

No plano imaginal, a árvore aparece ligada a diversos mitos arcaicos, fábulas e narrativas. Cauquelin (2002), constrói o lugar perfeito em sua mente, pelas histórias contadas pela sua mãe, passando a confrontar com o sentido da paisagem original, que nos é passado pela herança cultural (Cauquelin, 2002).

Portanto, a árvore é elemento fundamental da instituição da paisagem como natureza. Vemos aí uma das significações mitológicas da árvore. Os imaginais, as ideias e as emoções que se seguem a partir da presença da árvore na paisagem e na vida dos 
sujeitos imaginantes é uma busca pela sua conquista, reforçado ainda pela persistência do mito do paraíso, do qual a árvore participa diretamente. Segundo Jung, não é necessário haver um conhecimento consciente dos significados de um símbolo para que eles ajam de forma eficaz na imaginação dos sujeitos (Jung, 1963).

Com base na sabedoria milenar do Taoísmo, desde a introdução do livro I Ching feita por Carl Jung nas primeiras décadas do século XX para o Ocidente, a imagem do Taoísmo para o sujeito é a árvore. Além de enfatizar a intimidade do sujeito com a natureza, essa imagem ajuda o homem a conhecer a si mesmo: a cabeça são as folhas, os braços são os galhos, o tronco é o corpo e as pernas são as raízes.

\section{ÁRVORE COMO IMAGEM POÉTICA E SIMBÓLICA NA PAISAGEM}

Em seus estudos sobre a imaginação poética, a árvore não passa despercebida por Bachelard. O autor identifica os vegetais como indutores de devaneios particulares e dedica às árvores uma atenção especial em diversos trechos de alguns de seus livros, ressaltando que as imagens fundamentais relacionadas aos vegetais são elementos indispensáveis à constituição de uma doutrina da imaginação literária.

Bachelard nos informa que o vegetalismo da imaginação é lento, doce e repousante e que a árvore reúne e ordena os elementos mais diversos. A evasão onírica vegetante nos conduz ao ritmo lento, penetrante, às "lembranças dos devaneios ditosos" guardadas no vegetal (Bachelard, 1943).

Assim, Bachelard nos mostra que "o devaneio, ao contrário, é a abertura do mundo. As imagens que emergem do devaneio são valores a partir dos quais nós somos criados" (Bachelard, 1943). Deixemos agora nosso devaneio seguir a essência do imaginário arbóreo, pois a árvore é um ser que o sonho profundo nos remete para um onirismo profundo. Conforme Bachelard, na afirmação do poeta latino, Horácio, temos que: "o poema é uma imagem que fala, a imagem é um poema silencioso".

A árvore, elemento condensador e potencializador dos devaneios vegetais, fomenta o sentimento de engrandecimento da alma dos sujeitos imaginantes. Para Bachelard, "a árvore tem sempre um destino de grandeza", que ela propaga e interioriza (Bachelard, 2004). Ela ativa nosso espaço interior, que the rompe os limites; assim, ao penetrar no espaço intimo da árvore, sonhador e árvore crescem juntos.

Para Bachelard, a árvore é um objeto integrante, ou seja, um objeto que tem forças expressivas de integração, que serve para integrar imagens. Com o seu dinamismo indutor, a árvore está em todo lugar ao mesmo tempo, na terra e no ar, fazendo crer que a própria imaginação é uma árvore, pois tem as mesmas virtudes de caráter. Além disso, a árvore une o infernal ao celeste, o ar a terra e oscila do dia à noite (Bachelard, 2004). 
Deixando um pouco de lado a imagem poética bachelardiana, seguimos com Durand (1997), que, ao estudar os arquétipos fundamentais da imaginação humana, propôs um método de estruturação das imagens por constelações isomórficas, delineadas a partir da convergência de símbolos. Segundo esse autor, os símbolos constelam porque são desenvolvidos a partir de um mesmo tema arquetipical, ou seja, variações sobre um mesmo arquétipo.

Nessa categorização, a árvore demonstra o quanto ela é complexa em sua estrutura arquetípica, podendo ser classificada entre imagens ascensionais ou como ritmo cíclico. Durand, entretanto, apesar de verificar que Bachelard a classifica entre as imagens do primeiro grupo, ressalta que a intenção arquetípica, que lhe dá essa característica, atua como um complemento do simbolismo cíclico, considerando-a como a "fase ascendente do ritmo cíclico" (Durand, 1997).

A árvore pertence e é o símbolo principal da categoria (re)presentada pelo ímpeto ascendente do progresso temporal, que é uma fase cíclica que encaixa todos os outros ciclos como "figuras" e "esboços" do último processo. A árvore é indicativa de um sentido único do tempo e da história, reduzindo o ciclo à transcendência. Ela não consegue libertar-se do seu contexto cíclico e sazonal, no entanto, o arquétipo temporal da árvore é dominado pelo ciclo do progresso. "Todo progressismo é arborescente" (Durand, 1997).

A árvore coloca-se, portanto, novamente num limiar: a sua categorização junto aos outros símbolos vegetais é suplantada pela humanização de seu arquétipo trazida pela verticalidade, que orienta o devir e aproxima-o da estação vertical, passando do caráter cíclico dos vegetais ao progressista.

Durand afirma que a árvore, como coluna ou como chama, tem a tendência de sublimar-se, de verticalizar sua mensagem simbólica. A árvore-coluna estrutura a ideia de totalização cósmica a partir da verticalidade. A relação entre os mistérios e a divindade, envolvendo o sentido religioso atribuído às árvores.

Voltando ao aspecto cíclico, para Bachelard, a árvore é o ser do grande ritmo, com as suas manifestações mais ricas e seguras, renovando incessantemente o seu sonho cosmogônico (Bachelard, 1943). Ela representa o ritmo cíclico principalmente pelo processo natural da floração, da frutificação e da vegetação sazonal.

As árvores aparecem como bons símbolos, ante a sua profundidade, por obedecer aos grandes ritmos da natureza e por ser um bom instrumento para o sonho. As árvores também atuam como um forte simbolismo religioso.

O universalismo do simbolismo das árvores pode ser exemplificado, segundo Bloch, pelo universalismo da conceituação da vida (Bloch, 1998). Assim, as árvores são símbolos potentes de vitalidade, doadoras de energia, fontes de vida e estão relacionadas 
com a força, o poder de autorregeneração, a autossuficiência, a longevidade, a fertilidade, o ciclo de morte e renascença sucessivas, a imortalidade e a vida (Rival, 1998).

\section{CONSIDERAÇÕES FINAIS}

O estudo aqui apresenta, possibilita-nos vislumbrar algumas ressonâncias da imagem-árvore, em especial, a da Árvore da Páscoa no contexto da imagem propulsora de significados simbólicos em suas diversas nuanças na paisagem e no imaginário do lugar poético dos sujeitos.

A árvore como um objeto simbólico na paisagem é o que nos permite preencher as formas da paisagem com conteúdos pelo transporte de atributos comumente admitidos, ao invés de contemplá-la como um segmento de elementos justapostos (Cauquelin, 2002).

São as ressignificações da imagem-árvore que se apresentam em símbolos, em memória, em espiritualidade e em identidade do lugar poético na paisagem e, são acolhidas no contexto de cada sociedade humana (Crichyno, 2016).

Esse é um dos pontos que defendemos em nosso estudo e para o qual nossas breves considerações se voltaram, pois indica a capacidade da imagem-árvore de manter um nível de transcendentalidade com relação aos aspectos culturais, ou seja, na sua reverberação com relação às emoções dos sujeitos imaginantes (Crichyno, 2016).

O símbolo arbóreo não é apenas múltiplo, mas tem também a capacidade de flutuar entre significações diametralmente opostas, tais como: vida e morte, sagrado e profano, claro e escuro, refúgio e perigo, dia e noite, infernal e celeste, ar e terra.

Essas interações estão relacionadas às modulações da imagem-árvore para os sujeitos imaginantes, que fazem do devaneio arbóreo um devaneio particular, que excede em sua repercussão ao infinito e acolhe os temperamentos mais divergentes dos sujeitos e de suas estruturas socioculturais.

As árvores estão aí. Na realidade, sempre estiveram. A humanidade é que só agora começa a percebê-las melhor. Elas cobriram com um imenso manto verde a Terra desde os seus primórdios e as colocaram em ressonância direta com a vida cósmica. Foi assim que a prepararam para receber a vida humana (Maclean, 2008).

\section{Referências}

Bachelard, G. (2004). A Poética do Espaço. In: Os Pensadores, São Paulo: Abril Cultural, pp. 181-354

(2001). Poética do Devaneio. São Paulo: Ed. Martins Fontes.

(1943). L'Air et les Songes: Essai sur L'Imagination du Mouviment.

Paris: Librarie Jose Corti. 
Bergson, H. (1992). Leçons d'Esthetique, Psycologie et Métaphysique. Paris: Presses Universitaires de France.

. (1953). Matière et Mémories: Essai sur la Relation du Corps a L’Esprit. Paris: Presses Universitaires de France. Bibliotèque de Philosophie Contemporaine.

Bloch, M. (1998). Why Trees, Too, Are Good to the Think With: Towards and Anthropology of the Meaning of Life. In: Rival, Laura (Ed.) The Social Life of Trees: Anthropological Perspectives on Tree Symbolism. New York: Berg, pp. 39-55.

Cauquelin, A. (2002). L'Invencion du Paysage. Paris: Quadrige/PUF.

Crichyno, J. (2016). Fenomenologia do Lugar Poético no Imaginário Arbóreo do Parque do Flamengo. Tese de Doutorado. Programa de Pós-Graduação em Arquitetura e Urbanismo. Universidade Federal Fluminense. Niterói. 227p.

Dardel, E. (2011). O Homem e a Terra: Natureza da realidade Geográfica. Tradução de Werther Holzer. São Paulo: Ed. Perspectiva.

Davies, D. (2002). The Evocation Symbolism of Trees. In: Cosgrove, Denis, Daniels, Stephen. (Ed.) The Iconography of Landscape: Essays on the Symbolic Representation, Design and Use of Past Environments. Cambridge Studies in Historical Geography. Cambridge: University Press, pp. 32-42.

Durand, G. (1997). As Estruturas Antropológicas do Imaginário. São Paulo: Ed. Martins Fontes.

Gadamer, H. G. (1976). Verité et Méthode. Seuil.

Jung, C. G. (1964). Dialetique du moi et de L'Inconscient. Paris: Gallimard.

Lewis, C. A. (1930). Landscape in the Mind. In: Rodbell, Phillips D. (Ed.). Proceedings of Fourth Urban Forestry Conference. St. Louis, Missouri: The American Forest Association, pp. 33-34.

Maclean, D. (2008). O Chamado das Árvores. Tradução de: equipe de voluntários da Irdin Editora. Minas Gerais: Irdin.

Sansot, P. (1989). Memoire Collective et Perdurances: Nîmes Inondée. Les Annales de la Recherche Urbaine, Images et Memoire. Paris, n. 42, pp. 5-10.

Spirn, A. W. (1984). The Granite Garden: Urban Nature and Human Design. New York: Basic Books, Inc., Publishers.

Verjat, A. (1993). De L'Archetype et du Mithe: une approche nouvelle. Iris, Mithe et Modernité: théories et méthodes. Grenoble, n. 13, pp. 7-22.

Wunenbuger, J.J. (2002). La Vie des Images. Presses Universitaires de Strasbourg. Grenoble: Presses Universitaires de Grenoble. La Bibliothèque de L'Imaginaire.

\section{Notas sobre o autor}

Jorge Crichyno. Professor Doutor do Departamento de Urbanismo da UFF. Universidade Federal Fluminense. E-mail: jorgecrichyno@hotmail.com. 